\author{
Copying letters to patients
}

Access to medical information is going to be extended by recent Government proposals that patients who agree are sent copies of correspondence relevant to their illness and medical treatment. The National Health Service (NHS) Plan for England (Department of Health, 2000) has stated unequivocally that letters between clinicians about an individual patient's care will be copied to the patient as of right. No exceptions have been made and the plan did not suggest that patients suffering from a psychiatric illness are to be treated differently from any other group of patients. However, the Department of Health has recently stated its intention to fund a series of pilot projects to test some key concepts before the policy is fully implemented in 2004. A number of areas to be informed by pilot work have been identified. These include the style and content of letters, testing formats and language that patients find acceptable and particular issues concerning mental health, children and carers (www.doh.gov.uk/patientletters).

\section{What do patients want?}

The increasing involvement of patients and carers in decision-making is a welcome development in contemporary medical practice. There is abundant evidence that patients wish to be better informed about their illness, its prognosis and the various treatment options available. The more involved they feel, the more likely they are to adhere to treatment. They have a right to know what is written about them and can apply to see their clinical notes under the Data Protection Act 1988, although in practice few exercise this right. For their part, doctors realise that planning treatment should be a collaborative exercise with the patient (and key relatives if appropriate). They accept they need to address patients' questions about their illness in some detail. The information technology explosion has enabled the general public to become much more knowledgeable about medical matters than they used to be. Many clinicians have had experience of patients coming to a consultation armed with a substantial amount of medical information downloaded from the Internet and they could already have formed firm views about what treatment they wish to receive. These might or might not accord with the doctor's own preferences.

\section{The evidence}

Little is known about the implications for the doctorpatient relationship of sending patients copies of letters written to other health professionals. The evidence that is available suggests the practice is welcomed. In one of the earlier surveys (Gill \& Scott, 1986), newly-referred rheumatology out-patients were sent a copy of the letter to their general practitioner (GP). They strongly endorsed the practice from which they were thought to derive considerable benefit. However, there was much opposition from some GPs to even limited release of information. In a general practice study, Jelley et al (2000) sent patients copies of the referral letter to hospital out-patient clinics. The response was very positive and patients favoured this practice becoming routine. The authors subsequently adopted this policy and have reported continued patient satisfaction (Jelley et al, 2002). There were few reported concerns about understanding the letters and patients did not report increased anxiety, but felt reassured that their problem was being dealt with. Another practice that has met with approval is dictating letters in front of the patient (Hamilton et al, 1997) or the family in paediatric clinics (Lloyd, 1997).

Smith (2002), a neurologist, has described some of the pitfalls. In one letter to a GP he described a patient as 'enmeshed with her mother'. When the patient's mother eventually obtained a copy of the letter, the remark damaged the doctor-patient relationship and strained the trust between the GP and the family. Smith then resolved that future clinic letters would report the consultation solely, and would include only narrative and comments openly discussed.

\section{Implications for psychiatry}

A number of studies have specifically considered the implications for psychiatric practice. Letters written by psychiatrists usually contain considerably more personal detail than do letters written by clinicians in other specialties. Lengthy accounts of family relationships, academic attainments, career, psychosexual development and personality traits are commonplace. There often appears to be an inverse correlation between the length of a letter and the seniority of the doctor writing it. Patients might regard information of this nature as highly confidential and not appropriate for inclusion in a letter to another professional. Other topics to which patients might object include assessment of premorbid personality and a description of aetiological factors based on psychodynamic understanding. The whole diagnostic process in psychiatry is also open to challenge, given the absence of objective criteria. Even when operational diagnostic criteria are employed, eliciting mental state abnormalities depends on subjective clinical judgement with which the patient may disagree radically.

Asch et al (1991) conducted a controlled survey of psychiatric out-patients, one group of which had been 
sent copies of summary letters to their GP. Subsequent interviews indicated that the letters had been well received and patients who had been sent letters were special articles more satisfied with their consultations than were their control group counterparts. Similarly, Slaney \& Vaughan (1998) reported high levels of satisfaction among patients who were given access to the psychiatrist's initial report following a domiciliary or out-patient consultation.

However, the offer was withheld from over one-fifth of eligible patients because it was thought that revelation of a particular diagnosis would have a detrimental clinical effect. One patient who was allowed access was extremely angry about the opinion expressed and this subsequently soured the clinical relationship. Fitzgerald et al (1997) also reported approval of a letter-sharing scheme in a community mental health team as did Murray et al (2003) in out-patients, although they reported that letters were withheld from three out of 76 patients and information was omitted in 17 letters that were sent. Bernadt et al (1991) found a less favourable response in out-patients who were sent a copy of the main written summary that had originally been sent to their GP. Only half thought the summary provided helpful information and over a quarter were upset by what they read.

On an in-patient unit, access to psychiatric records was considered a beneficial practice for the great majority of those who availed themselves of the opportunity; it was also thought to be beneficial for the junior doctors who recorded the notes (Kosky \& Burns, 1995).

\section{Out-patient survey}

To explore the implications further a survey was conducted on 63 consecutive patients attending liaison psychiatry clinics at the Royal Free Hospital, London. All were sent copies of correspondence to the referring specialist and GP. A structured questionnaire was subsequently posted to each patient to enquire whether they approved of the practice. Patients were also asked to comment on whether they would like the letters to contain more information on certain aspects of the illness and background history.

Despite a reminder, only 33 patients replied (52\%). The respondents were overwhelmingly positive about the practice, 30 being in favour with only two opposed and one uncertain. One of the patients who disapproved took strong exception to the description of his premorbid personality. Only a minority of patients wished the letters to contain more details about their illness or their treatment. Most patients did not wish a more detailed description of their personal history, family history or previous mental health. The results are summarised in Table 1.

All these patients had been referred by specialists in secondary and tertiary care at a large teaching hospital. They had non-psychotic psychiatric illnesses and no patient had evidence of significant intellectual impairment. More objections might have been made if the letters had been sent to patients with psychotic disorders, early dementia or severe personality disorders, in which case the practice might have led to an irretrievable breakdown in the relationship between doctor and patient.

\section{Benefits and drawbacks}

There is a narrow path that will have to be followed if the recommendations of the NHS Plan are to be fulfilled without attracting complaints, threats or litigation and breakdown in what should be a trusting and therapeutic relationship, but at the same time avoiding the secrecy and paternalism of which doctors have previously been accused.

The evidence that is currently available on this topic suggests that it is a practice which is welcomed by the great majority of patients. Only a small minority object, but it is from this group that complaints will emanate. Copying letters to patients is in keeping with the greater openness that is being increasingly adopted in modern clinical practice. It can help the patient understand the nature of the illness, and provide detailed information about future management and investigations. It is well known that patients do not retain much important material that is discussed during a consultation and the receipt of a letter summarising the consultation can provide a useful source of information, covering many of the points that the patient might have forgotten. Having to send the patient a copy of a letter will almost certainly concentrate the writer's mind, and reduce the use of medical jargon and potentially offensive value judgements. By contrast, some important clinical information might be withheld, particularly details of personal development and family structure. A patient's wish needs to be respected if there is certain information that they do not want recorded in a letter. Similarly, information provided by a third party must be treated sensitively and might not be appropriate for inclusion. Clinicians might also be reluctant to express an opinion based on clinical judgement rather than on objective signs and investigations.

Most doctors will probably support this development but much more evaluation is required, especially within psychiatry, to assess its feasibility and to determine the types of clinical consultations following which copying a letter to the patient might not necessarily be a good idea. There are some areas of medicine where a blanket policy of sending copies of letters to patients 'as

Table 1. Summary of patients' responses

\begin{tabular}{lrrrr} 
& Yes & Uncertain & No \\
\hline Approved of receiving copies of letters & 30 & 1 & 2 \\
Wanted more details of illness & 11 & 8 & 14 \\
Wanted more details of treatment & 12 & 5 & 16 \\
Wanted more details of personal & 5 & 10 & 18 \\
$\quad$ history & & & \\
Wanted more details of family history & 4 & 4 & 19 \\
Wanted more details of previous & 8 & 6 & 19 \\
$\quad$ mental health & & &
\end{tabular}

Replies received $=33(52 \%)$ 
of right' will jeopardise the therapeutic relationship that should exist between doctor and patient. Community psychiatrists, old age psychiatrists and forensic psychiatrists are particularly likely to experience problems if letters are sent to patients whose view of their illness might differ radically from that of their doctor. If further studies are to be helpful, they need to be carried out with representative groups of patients with a variety of conditions. Within the mental health field, this will mean assessing the opinions of patients with psychotic illnesses, intellectual impairment and personality disorders, including those who have been treated under the Mental Health Act 1983.

\section{References}

ASCH, R., PRICE, J. \& HAWKS, G. (1991) BERNADT, M., GUNNING, L. \& Psychiatric out-patients' reactions to summary letters of their consultations. British Journal of Medical Psychology, QUENSTEDT, M. (1991) Patients' access to their own psychiatric records. BMJ, 303, 967 .
DEPARTMENT OF HEALTH (2000) The NHS Plan. London: DoH.

FITZGERALD, K., WILLIAMS, B. \& HEALY, D. (1997) Shared care? Some effects of patient access to medical communications. Journal of Mental Health, 6, 37-46.

GILL, M.W. \& SCOTT, D. L. (1986) Can patients benefit from reading copies of their doctors' letters about them? BMJ, 293, 1278-1279.

HAMILTON,W., ROUND A. \& TAYLOR, P. (1997) Dictating clinic letters in front of patients. BMJ, 314, 1416.

JELLEY, D. M. \& VAN ZWANENBERG, T. (2000) Copying GP referral letters to patients - a study of patients' views. British Journal of General Practice, 50, 657-658.

JELLEY, D. M. VAN ZWANENBERG,T. \& WALKER, C. (2002) Copying letters to

patients - a key initiative that needs planned implementation. BMJ, 325, 1359 (letter)

KOSKY, N. \& BURNS, T. (1995) Patient access to psychiatric records: experience in an in-patient unit. Psychiatric Bulletin, 19, 87-90.

LLOYD, B.W. (1997) A randomised controlled trial of dictating the clinic letter in front of the patient. BMJ, 314, 347-348.

MURRAY, G. K., NANDRA, H., HYMAS,

$N$., et al (2003) Copying letters to patients. BMJ, 326, 449.

SLANEY, M. \& VAUGHAN, P. J. (1998) Patient access to psychiatric assessment reports. Psychiatric Care, $\mathbf{5}$, 225-227.

SMITH, P. E. M. (2002) Letters to patients: sending the right message. BMJ, 324, 685 .

Geoffrey Lloyd Consultant Liaison Psychiatrist, Royal Free Hospital, London NW3 2QG 